\title{
Androgen levels and apoptosis in the testis during postnatal development of finasteride-treated male rat offspring
}

\author{
Agnieszka Kolasa-Wolosiuk ${ }^{1}$, Kamila Misiakiewicz-Has', \\ Irena Baranowska-Bosiacka ${ }^{2}$, Izabela Gutowska ${ }^{3}$, Barbara Wiszniewska ${ }^{1}$
}

${ }^{1}$ Department of Histology and Embryology, Pomeranian Medical University, Szczecin, Poland

${ }^{2}$ Department of Biochemistry and Medical Chemistry, Pomeranian Medical University, Szczecin, Poland

${ }^{3}$ Department of Biochemistry and Human Nutrition, Pomeranian Medical University, Szczecin, Poland

\begin{abstract}
Introduction. The hormone-dependent events that occur throughout the first wave of spermatogenesis, such as the establishment of the number of Sertoli cells (SCs) and spermatogonial stem cells (SSCs) within the seminiferous cords and the setting up of the blood-testis barrier, are important for adult male fertility. Any changes in the T/DHT ratio can result in male subfertility or even infertility. In this study we aimed to evaluate effects of paternal exposure to 5-alpha reductase type 2 inhibitor, finasteride on litter size, androgen levels and germ cell apoptosis in male offspring during postnatal development.

Material and methods. The subjects of the study were 7, 14, 21/22, 28, and 90-day-old Wistar male rats (F1:Fin) born from females fertilized by finasteride-treated rats. Offspring born from untreated parental animals were used as a control group (F1:Control). Animals and the collected testes were weighed, blood and intratesticular levels of T and DHT were measured by ELISA, and the apoptotic index of testicular cells was evaluated by TUNEL technique.

Results. We observed difficulties in obtaining male newborns from female rats fertilized by finasteride-treated male rats. In the F1:Fin rats, changes in the body and testes weights occurred, and a lower number of apoptotic cells was found during postnatal maturation of the seminiferous epithelium. Changes in androgen concentrations during the first spermatogenesis wave and adult life were also evident.

Conclusion. Finasteride treatment of male adult rats may not only cause a decrease in the fertility of parental rats, but also could lead to incorrect, androgen-sensitive course of spermatogenesis in their offspring. (Folia Histochemica et Cytobiologica 2015, Vol. 53, No. 3, 236-248)
\end{abstract}

Key words: male rats; finasteride treatment; offspring androgen levels; germ-cell apoptosis; TUNEL

\section{Introduction}

During the first week of postnatal life, the primitive seminiferous cords contain gonocytes (precursors of

\footnotetext{
Correspondence address: A. Kolasa-Wolosiuk, Ph.D., D.Sci. Department of Histology and Embryology Pomeranian Medical University

Powstancow Wielkopolskich 72, 70-111 Szczecin tel.: +48914661677

e-mail: agnieszka.kolasa@pum.edu.pl
}

spermatogonial stem cells, SCCs), SSCs, and supportive Sertoli cells (SCs) [1]. Between the first and sixth week, the first wave of spermatogenesis takes place in the rat gonad [1,2]. Throughout this period, spermatozoa production is limited because of massive cell apoptosis [3], and in this way the proper number of SSCs and SCs $[4,5]$ for sperm production in adult gonads is established [6]. Moreover, at about the $15^{\text {th }}$ to $18^{\text {th }}$ postnatal day, the physiological blood-testis barrier is created, the lumen of the seminiferous cords open, and the Sertoli cells undertake their secretory function $[6,7]$. 
The morphology and function of the testis is under the control of hypothalamic-pituitary-gonad axis and locally produced steroid hormones such as testosterone (T) and dihydrotestosterone (DHT), which is much more biologically active than $\mathrm{T}$ [8]. The irreversible reduction of T into DHT is carried out by $5 \alpha$-reductase [9]. The most common isoform in the male reproductive system is $5 \alpha$-reductase type $2(5 \alpha$-red2) [10]. Finasteride is a steroidal inhibitor of $5 \alpha$-red2 [11] that blocks the conversion of T into DHT and is often used for the treatment of prostate cancer or benign prostatic hyperplasia (BPH) at a dose $5 \mathrm{mg} /$ day. Moreover, dermatologists frequently use $1 \mathrm{mg}$ finasteride daily in the chronic therapy of prematurely balding young men (AGA; androgenetic alopecia) [12]. It has been postulated that long-term finasteride therapy, often lasting for many years, has no negative influence on androgen-dependent processes such as fertility or libido [13, 14]. However, many studies have documented contrary findings [15, 16]. In patients administered finasteride, a decrease in semen parameters [17-19], difficulties in fertilization [18], sexual dysfunction such as low libido, and problems with erection and orgasm are observed [20]. Some of these symptoms persist for many months after administration of the drug has ceased [20]. In spite of these persistent sexual side effects, patients also suffer from melancholy, depressive syndromes, and suicidal thoughts [21]. Other case reports reveal that low-dose finasteride results in sperm DNA damage (elevated sperm DNA fragmentation index) [22, 23]. Transmission electron microscopy studies revealed altered sperm morphology consistent with necrosis, and FISH data showed elevated frequencies of diploidy and sex chromosome disomy [24]. One year after the cessation of finasteride treatment, the meiotic pattern had not changed and elevated diploidy and sex chromosome disomy were still present; however, the motility and sperm morphology had improved [24]. Furthermore, it has been suggested that there is still no documented full-term pregnancy or live birth from couples in which the man received finasteride [22].

In rat, finasteride treatment decreased fertility connected with the affected function of the accessory glands [25] and promoted partial inhibition of spermatogenesis [26]. In studies of castrated male rats, $5 \alpha$-reductase inhibitors were found to have a detrimental effect on erectile function, which was restored with DHT [27, 28].

Nowadays, a great deal of interest has been focused on endocrine disruptors (EDs) that mimic or block sex hormones, disrupt homeostasis and hence can negatively influence reproductive system development and function $[29,30]$. Finasteride, as a drug that modulates activity of the key enzyme involved in metabolism of testosterone, can fit the definition of endocrine disruptor.

Taking together the fact that finasteride treatment can result in persistent sexual side effects and change androgens concentration similarly to endocrine disruptors, the aim of this preliminary study was to analyze the T and DHT levels and their possible correlation with germ cell apoptosis during testes postnatal maturation of progeny of paternal rats treated by finasteride.

\section{Material and methods}

Animals. The study was conducted on albino Wistar rats. Parental generation (F0) was used to obtain the next male generation (F1). The experiment was conducted in full accordance with Polish law and with the approval of the Local Ethics Committee for Scientific Experiments on Animals in Szczecin, Poland.

Parental generation was represented by 12 female and 10 male rats (for mating purposes only). At the beginning of the experiments, the rats were 12 weeks old. During the adaptation period ( 1 week) the animals were housed in cages ( 3 female or 1 male per cage) in the Animal Facility of Pomeranian Medical University. The room humidity was approximately $55 \%$, and the air temperature was $22 \pm 2^{\circ} \mathrm{C}$. The lighting, on a 12/12-hour cycle. After the adaptation, the males were randomly divided into two groups (F0:Control, $\mathrm{n}=4$; and F0:Fin, $\mathrm{n}=6$ ). Females and males from control group were not given any medicaments. The six male rats from F0:Fin group were given finasteride (Proscar ${ }^{\circledR}$, MSD, Carmlington, UK) $5 \mathrm{mg} / \mathrm{kg} / \mathrm{bw}$ daily. The finasteride was given once per day (in the morning) as a small pellet of finasteride powder stuck in bread. The pellet was served to each experimental parental male rat. The animals willingly ate the pellets from the hand of the person performing the experiments. The paternal control group (F0:Control) received the same bread pellet, but without finasteride. The dose of finasteride was the same as in our previous investigation [31] and as described by others [32, 33]. The period of finasteride treatment before mating lasted 56 days, according to the results of our previous study which demonstrated pathomorphological changes in the seminiferous epithelium [31]. Male rats received finasteride up to the end of the experiment (for 4-5 months). Once a week the animals were weighed, and finasteride dose was adequately adjusted.

We started mating couples from F0:Control and F0:Fin groups at the same time subsequently the age of the parental animals was comparable. Each mating pair was kept in one cage. After one week, the females were separated from the males, and each pregnant female rat was placed in a separate cage. Standard food and tap water were freely available. 
Generation of filial animals. The control group (F1:Control, $\mathrm{n}=30$ ) included the male rats born from the females fertilized by vehicle-treated male rats. The experimental group (F1:Fin, $\mathrm{n}=30$ ) were male rats that were born from females fertilized by finasteride-treated male rats. The objective of the experiment was to sample gonads and blood from $\mathrm{F} 1$ rats in 7, 14, 21, 28 and 90 postnatal day (PND) of life. The female pregnant rats also gave birth on weekends when sections were not possible, so groups of 22-day-old rats (22 PND F1:Control and 22 PND F1:Fin) were included in the experiment. Each age group included 5 male rats. Our experimental model of gonad maturity is justified by the fact that in the seminiferous epithelium of 7-day-old rats, only gonocytes, SCs, and SSCs are present. During maturation (i.e. successive weeks of the experiment), other generations of germ cells occur within SE [1, 2]. A completely mature gonad with spermatozoa production ability is found in 3-month-old rats (90 days old).

The time of pupils' collecting period was scheduled for 4-5 months to avoid aging of the parental generation. Due to the problem with obtaining male newborns of F1:Fin groups (the low number of pups in the litters, and elimination newborns by female rats) the mating of parental rats were performed one more time with the new purchased animals in the same designed way as described above.

After thiopental anesthesia $(120 \mathrm{mg} / \mathrm{kg}$ bw, i.p., Biochemie GmbH, Wien, Austria) the blood and left testes (5 animals per each age group of the F1 generation) were collected to measure the T and DHT concentration. The 5 right testes from newborns of each F1 group were used for TUNEL assay. Additionally, body and testis weights were measured. In each collected litters, the number of newborns just after birth was counted. The gender distribution was evaluated 1-2 weeks after birth and was checked one more time when the prepubertal animals were sacrificed. The males that formed 90-day-old group were separated from females at one month of age and counted.

Hormone assays. The frozen testes were taken from liquid nitrogen and placed in a thermobox $\left(-21^{\circ} \mathrm{C}\right)$. A small fragment of the tissue was placed in a metal homogenizer (previously cooled in a container with liquid nitrogen) and liquid nitrogen was poured over it 2-3 times; it was then fragmented with 4-5 hammer blows against a metal mandrel (also previously cooled in a container with liquid nitrogen). The pulverized and frozen sample (with volume equal to that of approximately $1 \mathrm{mg}$ of protein) was then placed with a cooled spoon in an Eppendorf tube containing $100 \mu \mathrm{L}$ phosphate-buffered saline (PBS), according to manufacturer's instruction, previously cooled to $4^{\circ} \mathrm{C}$. After brief vortexing, homogenization was carried out with a knife homogenizer whipper for about $15 \mathrm{~s}$. The extract mixtures were centrifuged $\left(3,000 \times g\right.$ for $10 \mathrm{~min}$ at $\left.4^{\circ} \mathrm{C}\right)$ and the supernatants were stored at $-80^{\circ} \mathrm{C}$ until being used for hormone assays.
Blood was obtained from the rat's heart using EDTA as an anticoagulant. The blood was centrifuged for $15 \mathrm{~min}$ at 1,000 $\times g$ at $8^{\circ} \mathrm{C}$ and plasma was collected and stored at $-80^{\circ} \mathrm{C}$ for hormone analysis.

A standard sandwich ELISA assay was performed on testes' homogenates and blood plasma using the rat specific DHT and T ImmunoAssay System kit (CUSABIO; CBS-E05100r and CBS-E07879r), according to the manufacturer's instructions. This assay employs the competitive inhibition enzyme immunoassay technique. The microtiter plate provided in this kit has been pre-coated with goat-anti-rabbit antibody. Standards or samples are added to the appropriate microtiter plate wells with an antibody specific for DHT or T and horseradish peroxidase (HRP) conjugated with DHT or T. The competitive inhibition reaction is launched between with HRP labeled DHT or T and unlabeled DHT/T with the antibody. A substrate solution is added to the wells and the color develops in opposite to the amount of DHT or T in the sample. The color development is stopped and the intensity of the color is measured. The procedure was performed using an Asys UVM 340 microplate reader (Asys Hitech GmbH, Wien, Austria). The DHT and T protein concentration was normalized to total protein levels as measured by a BCA kit (Pierce, Life Technologies, Warsaw, Poland), using bovine albumin as a standard. The detection range for T was $0.13-$ $-25.6 \mathrm{ng} / \mathrm{mL}$ with a sensitivity $0.06 \mathrm{ng} / \mathrm{mL}$; for DHT, the detection range was $10-2,000 \mathrm{pg} / \mathrm{mL}$ and the sensitivity $5 \mathrm{pg} / \mathrm{mL}$.

Apoptosis in situ detection. The analysis was carried out using a TACS ${ }^{\circledR} 2$ TdT-DAB In Situ Apoptosis Detection Kit (cat. no. 4810-30-K; TRAVIGEN ${ }^{\circledR}$ Inc., Gaithersburg, MD, USA). Deparaffinized sections of formalin-fixed testes were incubated with proteinase K solution (15 min at RT), rinsed in PBS twice, and incubated for 5 minutes with a mixture of methanol (POCH, Poland) and $30 \%$ hydrogen peroxide (Sigma-Aldrich) $\left(45 \mathrm{~mL} \mathrm{CH}_{3} \mathrm{OH}+5 \mathrm{~mL} \mathrm{H}_{2} \mathrm{O}_{2}\right)$. For the next 5 minutes, the slides were covered with TdT Labeling Buffer and then incubated with Labeling Reaction Mix (mixture of TdT dNTP Mix, TdT Enzyme, $\mathrm{Mn}^{2+}$, TdT Labeling Buffer) for one hour. The negative control was incubated with Labeling Reaction Mix omitting TdT Enzyme. Then, the reaction was inhibited by TdT Stop Buffer, slides were rinsed in PBS and labeled with streptavidin conjugated with horseradish peroxidase. The chemicals needed to prepare: proteinase K solution, TdT Labeling Buffer, Labeling Reaction Mix, TdT Stop Buffer and streptavidin conjugated with HRP were from TRAVIGEN ${ }^{\circledR}$. To visualize the effect of the reaction (places of DNA split), 3,3'-diaminobenzidine was added. Positive staining was defined under Leica DM5000B microscope (Leica, Wetzlar, Germany) as brown pigmentation of the cell nucleus. The apoptotic cell count was evaluated as the number of TUNEL-positive cells in 10 seminiferous tubules analyzed in five testis sections from each F1:Control and F1:Fin group of rats. 
Table 1. The number of collected newborns born from females fertilized by control and finasteride-administrated male rats with detailed number of males and females within each litter

\begin{tabular}{|c|c|c|c|c|c|c|}
\hline \multirow{3}{*}{$\begin{array}{l}\text { Number } \\
\text { of the litter }\end{array}$} & \multirow{2}{*}{\multicolumn{2}{|c|}{$\begin{array}{c}\text { F1:Control } \\
\text { Pups per liter }\end{array}$}} & \multirow{3}{*}{ Total } & & & \multirow{3}{*}{ Total } \\
\hline & & & & \multicolumn{2}{|c|}{ Pups per liter } & \\
\hline & Male & Female & & Male & Female & \\
\hline 1. & 8 & 3 & 11 & 3 & 6 & 9 \\
\hline 2. & 4 & 6 & 10 & 3 & 2 & 5 \\
\hline 3. & 6 & 7 & 13 & 1 & - & $1^{\mathrm{a}}$ \\
\hline 4. & 2 & - & 2 & 2 & 2 & $4^{b}$ \\
\hline 5. & 7 & 5 & 12 & 2 & 1 & 3 \\
\hline 6. & 3 & 5 & 8 & 2 & 4 & $6^{c}$ \\
\hline 7. & 6 & 1 & 7 & 4 & 4 & 8 \\
\hline 8. & 6 & - & 6 & 3 & 3 & 6 \\
\hline 9. & 4 & 9 & 13 & 3 & 7 & 10 \\
\hline 10. & 5 & 2 & 7 & 1 & 6 & 7 \\
\hline 11. & 10 & 1 & 11 & 2 & 5 & 7 \\
\hline 12. & 4 & 8 & 12 & 1 & 1 & 2 \\
\hline 13. & 6 & 7 & 13 & 5 & 7 & 12 \\
\hline 14. & 3 & 5 & 8 & 4 & 6 & 10 \\
\hline Total & 74 & 59 & 133 & 36 & 54 & 90 \\
\hline
\end{tabular}

F1:Control, F1:Fin — rat offspring born from females fertilized by the control or finasteride-treated male rats, respectively. a,b,c — almost all, half of all, one third of newborns in litter was eaten by female, respectively

Statistical analysis. The results were analyzed using Statistica 6.1 software (StatSoft, Krakow, Poland). The arithmetical means and SDs were calculated for each of the parameters. The normal distribution of the results for the individual variables was obtained using the Shapiro-Wilk test. As most of the distributions deviated from a normal distribution, nonparametric tests were used for further analyses. To assess the differences between the investigated groups, the nonparametric Mann-Whitney $U$-test was used. The probability $\mathrm{p} \leq 0.05$ was considered statistically significant. Correlations between the parameters were examined with Spearman's rank correlation coefficient $\left(\mathrm{r}_{\mathrm{s}}\right)$.

\section{Results}

\section{Number of pups per litter}

During the experiment 28 litters (14 in F1:Control, $\mathrm{n}=133$; and 14 in F1:Fin, $\mathrm{n}=90$ ) were collected (Table 1). The number of pups in the litters of the F1:Fin groups was lower than in control group (on average $6.4 \mathrm{vs}$. 9.5 pups per litter, respectively). The procreation process in this group had to be repeated many times, and three times the pups were eaten by the females fertilized by the finasteride-treated male rats. We did not notice this behavior in the control group. Moreover, in many litters, the female offspring of the F1:Fin generation predominated (60\% $q)$, in contrast to the F1:Control group (45\% $q)$.

\section{Body and testis weight}

The offspring of rats in both the F1:Control and the F1:Fin groups showed increasing body weight throughout the experiment, over the course of natural development. This obvious correlation was corroborated using Spearman's $R$-test $\left(\mathrm{r}_{\mathrm{s}}=0.97, \mathrm{r}_{\mathrm{s}}=0.95\right.$ respectively and $p=0.0001)$. The statistically significant higher body weight of F1:Fin vs. F1:Control was observed in 7, 14, and 90 PND (Table 2).

Testis weight increased over time in both the F1:Control and the F1:Fin groups. A statistically significant positive correlation between the increase in testis weight and animal age was demonstrated by Spearman's $R$-test (F1:Control $\mathrm{r}_{\mathrm{s}}=0.96 ; \mathrm{F} 1$ :Fin $\mathrm{r}_{\mathrm{s}}=0.97$; $\mathrm{p}=0.0001)$. Additionally, statistically significant differences were noticed in testis weight between the F1:Control and the F1:Fin groups of rats at 14, 22, 28, and 90 days after birth. A higher weight was characteristic of the testis of the 14 PND, 22 PND, and 90 PND rats in the F1:Fin group, while in the 28 PND rats of the F1:Control group, the testes were 
Table 2. Body and testis weight of rat offspring born from females fertilized by control or finasteride-treated male rats

\begin{tabular}{|l|c|c|c|c|c|c|}
\hline & \multicolumn{3}{|c|}{ Body weight [g] } & \multicolumn{2}{c|}{ Testis weight [mg] } \\
\hline Age & F1:Control & F1:Fin & $\begin{array}{c}\text { \% of change vs. } \\
\text { F1:Control }\end{array}$ & F1:Control & $\begin{array}{c}\text { F1:Fin of change vs. } \\
\text { F1:Control }\end{array}$ \\
\hline 7 PND & $17.45 \pm 2.69^{\mathrm{a}}$ & $20.23 \pm 2.74^{\mathrm{a}}$ & $\uparrow 16 \%$ & $16.07 \pm 2.86$ & $15.56 \pm 2.59$ & $\uparrow 3.2 \%$ \\
\hline 14 PND & $28.34 \pm 4.63^{\mathrm{b}}$ & $43.50 \pm 5.64^{\mathrm{b}}$ & $\uparrow 53.5 \%$ & $52.53 \pm 6.56^{\mathrm{a}}$ & $69.71 \pm 13.10^{\mathrm{a}}$ & $\uparrow 32.7 \%$ \\
\hline 21 PND & $48.25 \pm 2.47$ & $46.61 \pm 3.99$ & $\downarrow 3.4 \%$ & $137.32 \pm 15.19$ & $139.41 \pm 20.87$ & $\uparrow 1.5 \%$ \\
\hline 22 PND & $45.00 \pm 1.4$ & $46.00 \pm 2.24$ & $\uparrow 2.2 \%$ & $129.24 \pm 7.74^{\mathrm{a}}$ & $142.69 \pm 5.29^{\mathrm{a}}$ & $\uparrow 10.4 \%$ \\
\hline 28 PND & $63.33 \pm 11.93$ & $62.86 \pm 4.72$ & $\downarrow 0.7 \%$ & $265.44 \pm 22.11^{\mathrm{a}}$ & $244.36 \pm 23.89^{\mathrm{a}}$ & $\downarrow 7.9 \%$ \\
\hline 90 PND & $295.00 \pm 42.42^{\mathrm{b}}$ & $371.68 \pm 45.09^{\mathrm{b}}$ & $\uparrow 25.9 \%$ & $1449.6 \pm 13.85^{\mathrm{a}}$ & $1732.17 \pm 94.41^{\mathrm{a}}$ & $\uparrow 19.5 \%$ \\
\hline
\end{tabular}

F1:Control, F1:Fin - rat offspring born from females fertilized by the control or finasteride-treated male rats, respectively. Values express arithmetic means $\pm \mathrm{SD}(\mathrm{n}=5$ per each age group). The common superscripts within row denote statistically significant differences between compared groups evaluated by the Mann-Whitney $U$-test: ${ }^{\mathrm{a}} \mathrm{p}<0.01,{ }^{\mathrm{b}} \mathrm{p}<0.001$. The comparisons of F1:Fin $v s$. F1:Control are expressed as percentages of decrease $(\downarrow)$ or increase $(\uparrow)$. PND - postnatal day

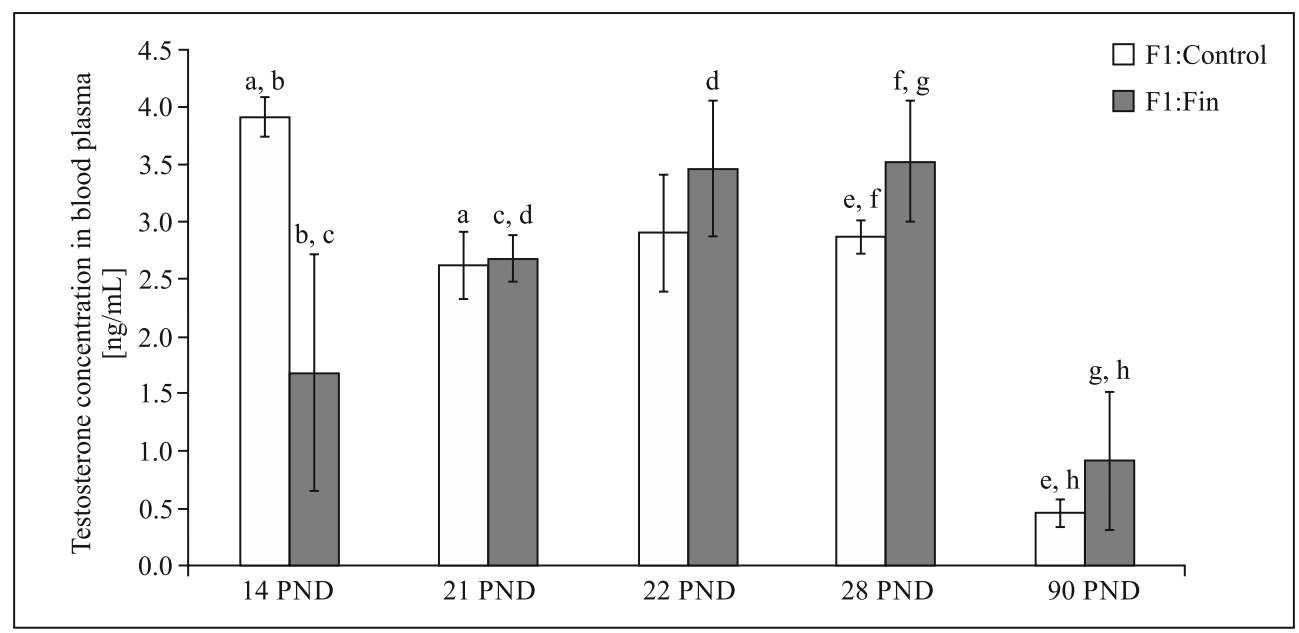

Figure 1. Testosterone concentration in blood plasma of control offspring and rats born from females fertilized by finasteride-treated male rats. F1:Control, F1:Fin — rat offspring born from females fertilized by the control or finasteride-treated male rats, respectively. Values are expressed as arithmetic mean, bars represent $\pm \mathrm{SD}$; differences were evaluated by the Mann-Whitney $U$-test ( $\mathrm{n}=5$ per each age group). The common letters denote statistically significant differences between each compared groups: ${ }^{\mathrm{d}} \mathrm{p}<0.01,{ }^{\mathrm{a}, \mathrm{b}, \mathrm{c}, \mathrm{f}} \mathrm{p}<0.001,{ }^{\mathrm{e}, \mathrm{g}, \mathrm{h}} \mathrm{p}<0.0001$. PND — postnatal day

notably heavier by about $7.9 \%$ in comparison to the F1:Fin (Table 2).

\section{Hormone levels}

\section{Serum concentration of androgens}

During the first weeks of development, the serum androgen levels fluctuated, and in immature rats showed much higher values then in the mature animals (Figures 1 and 2). The statistically significant differences in T levels between F1:Fin and F1:Control rat groups on the days following postnatal development were noticed at $14^{\text {th }}$ PND (2.3 times lower than in control), $28^{\text {th }} \mathrm{PND}$ (increase by $23 \%$ ), and $90^{\text {th }}$ PND (increase by $98 \%$ ) (Figure 1).
To compare F1:Fin with the F1:Control rats in the following days of the experiment, statistically significant differences in DHT levels were found for at 14, 22, and 90 PND. In F1:Fin group of rats, on the $14^{\text {th }}$ PND serum level of DHT was 2 times lower, on the $22^{\text {nd }}$ PND increased by ca. $30 \%$, and on the 90 PND declined by 1.6 times in comparison to control (Figure 2).

The statistical analysis showed a significant strong negative correlation of the plasma $\mathrm{T}$ concentration between the early developmental period and the period of sexual maturity in the F1:Control $\left(\mathrm{r}_{\mathrm{s}}=-0.87\right.$, $\mathrm{p}=0.00001)$ and F1:Fin $\left(\mathrm{r}_{\mathrm{s}}=-0.52, \mathrm{p}=0.00005\right)$ groups. Moreover, analysis of Spearman's rank correlation coefficient showed a strong negative correlation between plasma DHT concentration 


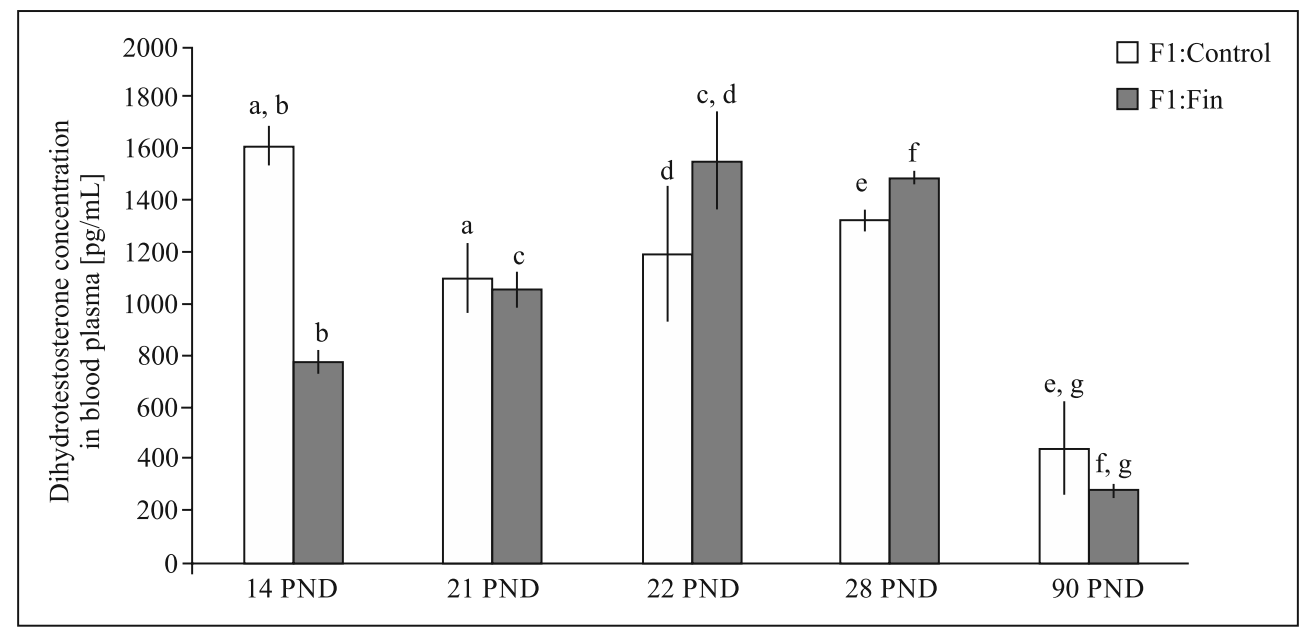

Figure 2. Dihydrotestosterone concentration in blood plasma of control offspring and rats born from females fertilized by finasteride-treated male rats. F1:Control, F1:Fin — rat offspring born from females fertilized by the control or finasteride-treated male rats, respectively. Values are expressed as arithmetic mean, bars represent $\pm \mathrm{SD}$; differences were evaluated by the Mann-Whitney $U$-test ( $=5$ per each age group). The common letters denote statistically significant differences between each compared groups: ${ }^{\mathrm{a}-\mathrm{g}} \mathrm{p}<0.001$. PND - postnatal day

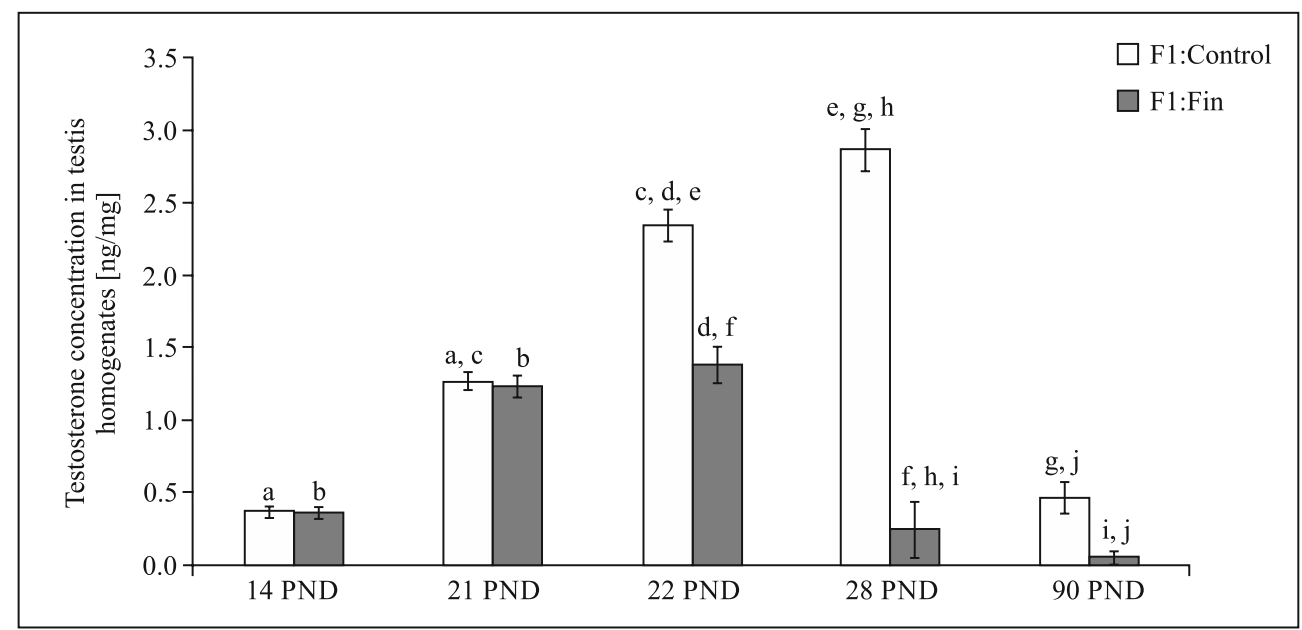

Figure 3. Testosterone concentration in testis homogenates of control offspring and born from females fertilized by finasteride-treated male rats. F1:Control, F1:Fin — rat offspring born from females fertilized by the control or finasteride-treated male rats, respectively. Values are expressed as arithmetic mean, bars represent \pm SD; differences were evaluated by the Mann-Whitney $U$-test ( $\mathrm{n}=5$ per each age group). The common letters denote statistically significant differences between each compared groups: ${ }^{\mathrm{g}} \mathrm{p}<0.0001,{ }^{\mathrm{a}-\mathrm{f}, \mathrm{h}-\mathrm{j}} \mathrm{p}<0.001$. PND - postnatal day.

and the time of development in the F1:Control $\left(\mathrm{r}_{\mathrm{s}}=-0.89, \mathrm{p}=0.00001\right)$ and F1:Fin $\left(\mathrm{r}_{\mathrm{s}}=-0.72, \mathrm{p}=\right.$ $0.00001)$ groups of rats; the general differences in the evaluated parameters were quite similar to the results describing the T levels.

\section{Concentration of androgens in the testicular tissue} The highest levels of intratesticular androgens were observed in four-week-old rats; the hormone concentrations were higher in immature gonads then in the mature gonads (Figures 3 and 4). A comparison of the F1:Fin and F1:Control groups demonstrated a statistically significant reduction in the intratesticular T on $22^{\text {nd }}$ PND, $28^{\text {th }}$ PND and $90^{\text {th }}$ PND (1.7 times, 12 times and 9.2 times, respectively) (Figure 3 ).

Generally, fluctuations in DHT levels were observed both in the control and the finasteride-offspring rats (Figure 4). Statistically significant decrease in intratesticular DHT levels was observed in F1:Fin groups at $21^{\text {st }} \mathrm{PND}, 22^{\text {nd }} \mathrm{PND}$, and $90^{\text {th }} \mathrm{PND}(3.3,3.7$ and 4 times, respectively) compared to the respective F1:Control animals. 


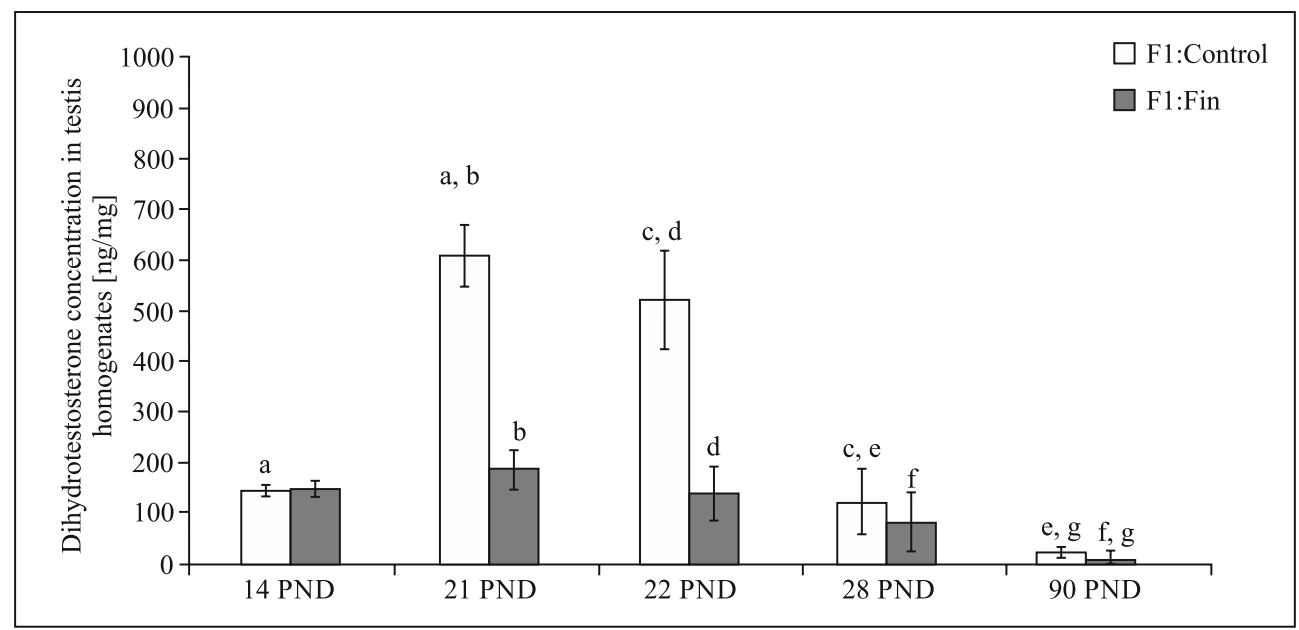

Figure 4. Dihydrotestosterone concentration in testis homogenates of control offspring and rats born from females fertilized by finasteride-treated male rats. F1:Control, F1:Fin — rat offspring born from females fertilized by the control or finasteride-treated male rats, respectively. Values are expressed as arithmetic mean, bars represent $\pm \mathrm{SD}$; differences were evaluated by the Mann-Whitney $U$-test ( $n=5$ per each age group). The common letters denote statistically significant differences between each compared groups: ${ }^{\mathrm{a}-\mathrm{g}} \mathrm{p}<0.001$. PND - postnatal day
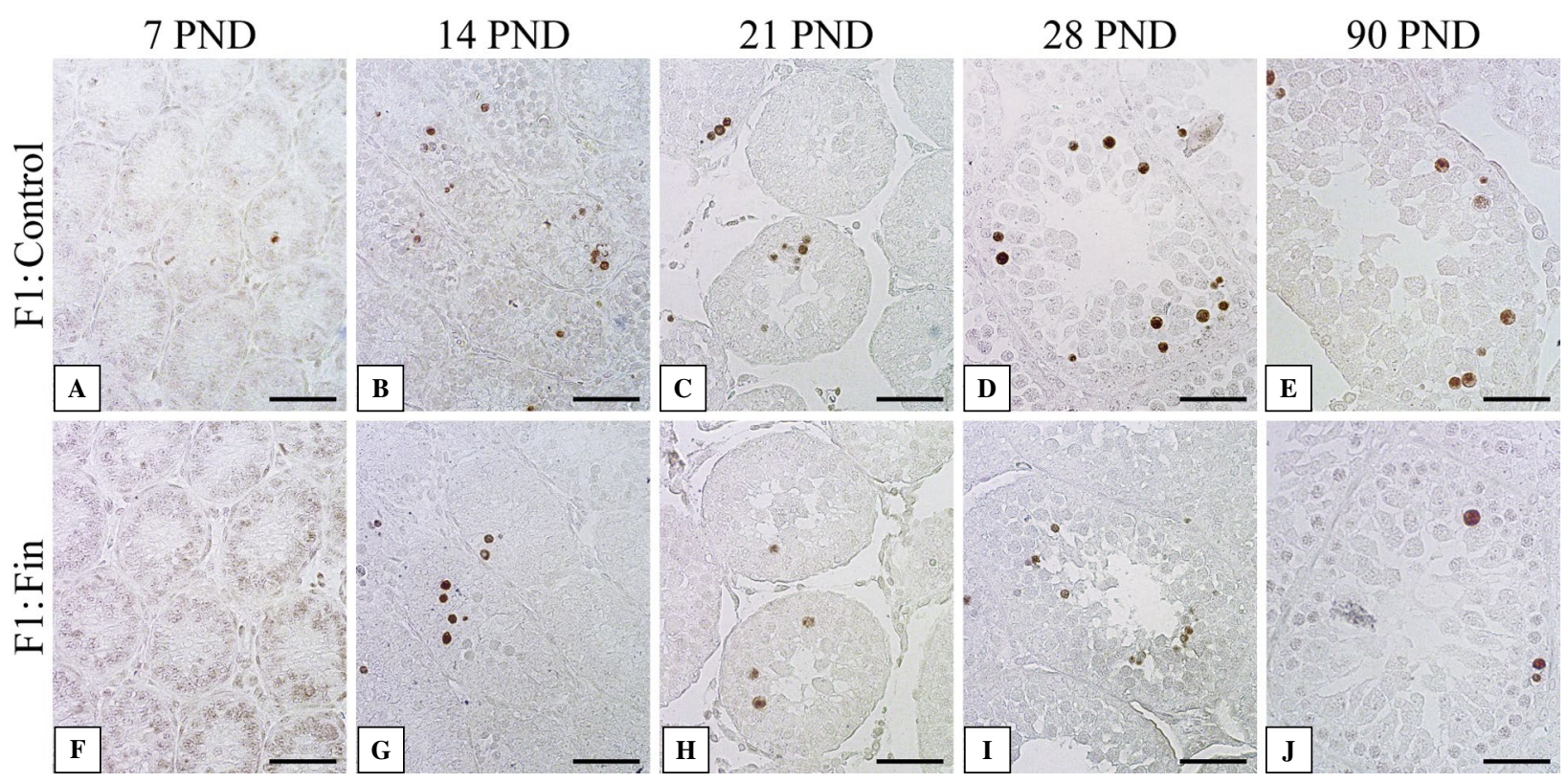

Figure 5. Apoptosis within the testis of rat offspring born from females fertilized by control (A-E) and finasteride-administrated (F-J) male rats detected by TUNEL method. Brown-stained nuclei indicate the apoptosis of germ cells in seminiferous epithelium. F1:Control, F1:Fin — rat offspring born from females fertilized by the control or finasteride-treated male rats, respectively ( $\mathrm{n}=5$ per each age group). Scale bar: $50 \mu \mathrm{m}$. PND - postnatal day

Statistical test showed a statistically significant strong negative correlation between testicular $\mathrm{T}$ concentration and developmental time only in F1:Fin rats $\left(r_{s}=-0.73, p=0.00001\right)$. The postnatal changes in DHT levels correlated negatively with time in the F1:Control $\left(\mathrm{r}_{\mathrm{s}}=-0.52, \mathrm{p}=0.00015\right)$ and F1:Fin $\left(r_{s}=-0.74, p=0.00001\right)$ groups of rats.

\section{TUNEL analysis}

In seven-day-old rats of both the F1:Control and the F1:Fin group, apoptosis was very sporadic (Figure 5A, F), on average, there were 0.27-0.28 TUNEL-positive cell for each cross-section of seminiferous tubule (Table 3). 
Table 3. The number of TUNEL-positive cells per cross-section of seminiferous tubule from the testis of the control and finasteride offspring rats

\begin{tabular}{|l|c|c|c|c|c|c|}
\hline Postnatal age & 7 PND & 14 PND & 21 PND & 22 PND & 28 PND & 90 PND \\
\hline F1:Control & $0.27 \pm 0.02$ & $0.49 \pm 0.09$ & $0.7 \pm 0.10$ & $11.6 \pm 0.83^{\mathrm{b}}$ & $1.02 \pm 0.13^{\mathrm{a}}$ & $1.16 \pm 0.10^{\mathrm{a}}$ \\
\hline F1:Fin & $0.28 \pm 0.07$ & $0.52 \pm 0.12$ & $0.76 \pm 0.14$ & $3.1 \pm 0.07^{\mathrm{b}}$ & $0.68 \pm 0.02^{\mathrm{a}}$ & $0.72 \pm 0.05^{\mathrm{a}}$ \\
\hline \% of change $\boldsymbol{v s .}$ F1:Control & $\uparrow 3.7 \%$ & $\uparrow 6.12 \%$ & $\uparrow 8.6 \%$ & $\downarrow 73.3 \%$ & $\downarrow 33.3 \%$ & $\downarrow 37.9 \%$ \\
\hline
\end{tabular}

F1:Control, F1:Fin — rat offspring born from females fertilized by the control or finasteride-treated male rats, respectively. Values are expressed as arithmetic means $\pm \mathrm{SD}$; differences were evaluated by the Mann-Whitney $U$-test ( $\mathrm{n}=5$ per each age group). The common superscripts within row denote statistically significant differences between compared groups: ${ }^{\mathrm{a}} \mathrm{p}<0.01,{ }^{\mathrm{b}} \mathrm{p}<0.0001$. The comparisons of F1:Fin $v s$. F1:Control are expressed as percentages of decrease $(\downarrow)$ or increase $(\uparrow)$. PND — postnatal day
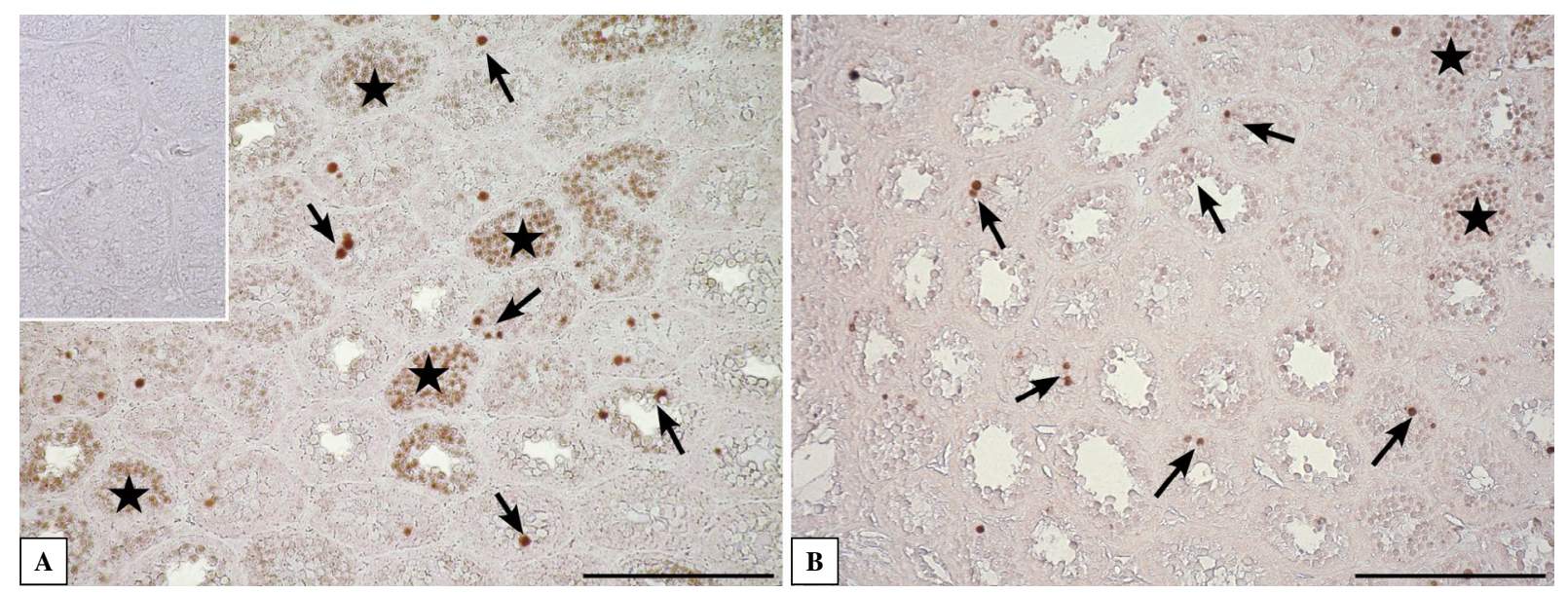

Figure 6. Apoptosis within the testis of 22-day-old rat offspring born from females fertilized by control (A) and finasteride-administrated (B) male rats detected by the TUNEL method. Black arrows indicate seminiferous tubules with single brown-stained nuclei of apoptotic germ cells in the seminiferous epithelium; black asterisks show cross-sections of seminiferous tubules with a great number of TUNEL-positive cells. Insert in upper left corner of A - a negative control. F1:Control, F1:Fin — rat offspring born from females fertilized by the control or finasteride-treated male rats, respectively ( $\mathrm{n}=5$ per each age group). Scale bar: $200 \mu \mathrm{m}$

In the following postnatal days of testis development (Figure 5B-D, G-I), during the first wave of spermatogenesis, apoptosis intensified over time in both the groups of rats, though somewhat more (Table 3 ) in the F1:Fin group (Figure 5G-I) than in the control rats (Figure 5B-D), up to the third week of development; and in F1:Fin, this parameter declined in the $28^{\text {th }}$ day of life. The apoptotic cells seemed to be large, round primary spermatocytes, probably pachytene spermatocytes. In the gonads of the sexually mature (90 PND) F1:Control and F1:Fin rats, only the cell nuclei of a few seminiferous tubules manifested a positive result in the TUNEL analysis (Figure 5E, J) and the scores were similar for both groups, with an average of 1.16 and 0.72 cells per tubule (Table 3 ).

In both groups of 22-day-old rats, the apoptosis process was statistically significantly greater, and was found in some whole cross-sections of seminiferous tu- bules or in single cells in the seminiferous epithelium (Figure 6A, B). The statistically significant escalation of the apoptotic index was much more noticeable in the testis of F1:Control rats (Table 3).

\section{Discussion}

Currently, the observed decreasing semen quality and increasing male reproductive problems are the result of many etiological factors associated with lifestyle or exposure to radiation, stimulants, environmental agents, and medicines [34-36]. The regulation of the development of male reproductive system and its correct function is under the control of several mechanisms sensitive to both endogenous and exogenous factors which begin to operate during fetal life [37]. It has been also shown that endocrine disruptors have transgenerational effect on male 
fertility [38-40]. In utero dose-dependent exposure to finasteride induced permanent effects on androgen-sensitive end points such as anogenital distance, nipple retention and malformations of male rat and rhesus monkey reproductive tract (absence of prostate lobes, ectopic testes, small scrotum, small penis, hypospadias) [41, 42]. In addition, finasteride is still considerate as a drug, with the possibility of its teratogenic effects on semen quality that was tested experimentally in a primate model [41]. Prahalada et al. administrated to monkeys throughout pregnancy daily doses of finasteride, within and above range of semen levels of the drug, and effects on the offspring were assessed. In that study no abnormalities were observed in the offspring, even at doses 60-750 times higher than levels found in the semen of men treated with recommended dose of finasteride, suggesting a large safety margin for potential human exposures [41]. However, results of some other reports suggest that finasteride could be recognized as a medicine that produces persistent sexual side effects [16-20] with a negative impact on human fertility [43-45]. Thus, finasteride that inhibits reduction of T to DHT and hence changes the androgen ratio, could also be considered as one of reprotoxicants.

Caution has been also advised regarding the use of finasteride by male members of couples who plan to have children [44]. Finasteride-induced secondary infertility is speculated to be correlated with higher sperm DNA fragmentation indices [22, 23], 1818XY diploidy, and 19XY disomy [24]. Approximately 95\% of the length of the human Y chromosome is taken up by a nonrecombining region (NRY) that contains the majority (50-60\%) of the encoding genes inherited from father to son. Some of these genes are crucial for fertility: these include AZF1 (azoospermia factor 1), BPY2 (basic protein on the Y chromosome), DAZ1 (deleted in azoospermia), TSPY (testis specific protein), UTY (ubiquitously transcribed TPR gene on the Y chromosome), SRY (sex-determining region); Y chromosome also contains so-called male-specific regions associated with increased risk of cardiovascular disease or testis and prostate cancer [46-48]. Most of data associated with animals male reproductive traits came from studies on mouse, less from studies on rat or cattle [49-51]. Also in animals, some of Y-chromosomal genes are needed for proliferation of spermatogonial stem cell and normal sperm morphology [49], some of them could be functional in rat and non-functional in mouse [50] or are highly conserved in some mammalian species [52].

Although in our study, we did not perform any analysis of the spermatozoa genome, the difficulties in obtaining pups from female rats fertilized by fina- steride-treated male rats could be associated with molecular abnormalities in the sperm, as shown in other studies [22-24]. Firstly, we observed the low number of pups in the litters. We thus needed to repeat the procreation process many times. This fact could be associated with weak semen quality (probably a side-effect of finasteride). We also observed the elimination of newborns by female rats. The phenomenon of infanticide exists in the animal world: mothers tend to kill deformed, sick or weak young pups, only allowing healthy ones to survive [53]. Moreover, female pups predominated in many litters in our experiment. As was mentioned above, even a low dose of finasteride might exert a negative effect on sperm DNA integrity [22-24]; thus, the unequal distribution of sexes in the litters may have been caused by some genetic changes in the spermatozoa chromosomes of the finasteride-treated rats. Possibly, finasteride like endocrine disruptors could induce transgenerational effect. The experimental treatment of male mice by dioxin (TCDD) produced the alternation in the sex ratio of filial generation [54], and exposure of young men to dioxins accumulated in the environment increased probability of female births [55]. Additionally, the changed gender distribution strongly correlated with paternal not maternal dioxin exposition [56]. Moreover, Anway et al. showed that the in utero exposure of rat fetuses to vincozolin (anti-androgenic endocrine disruptor) resulted in decrease of male pups' number per litter of subsequent F1-F4 rats' generation [39] similarly in our F1:Fin generation. Additionally, our results suggest that finasteride treatment could increase the mortality of pups in the F1:Fin generation in contrast to Anway et al. [39] study. Therefore, according to study by Trasler and Doerksen [57] it should be more often emphasized that not only maternal but also paternal exposure to harmful chemicals may entail the developmental changes in offspring.

The surviving F1:Fin offspring developed well, and had slightly different body and testis weights to the F1:Control animals of the same age. During the first 14 postnatal days, F1:Fin rats were significantly heavier. Also adult, 90-day-old rats from the F1:Fin group were heavier then control rats. These observations can be associated with the modulation of adipose tissue metabolism by androgens [58], and therefore could be affected by changes in T/DHT ratio observed in our experiment. Interestingly, also testis weight of the 14, 22, and 90-day-old F1:Fin rats were statistically heavier than that of the similarly aged rats in the F1:Control group, proportionally to the higher body mass of these animals.

Apoptosis is a normal physiological process that occurs within testes [5, 59], and the first round of spermatogenesis exhibits massive apoptosis of germ 
cells $[3,6,59]$. In rodents such as golden hamster, apoptosis starts on the $14^{\text {th }}$ fetal day, two days prior to birth [60]. In rat testis frequency of apoptosis increase during the prepubertal period (the first 3-4 weeks) of life [7], and this phenomenon was also observed in our study: apoptosis sporadically occurred in testes of 7-day-old rats, and intensified over time during the first wave of spermatogenesis in both the F1:Control and F1:Fin rats. Similarly to other authors [3], during the first wave of spermatogenesis we observed numerous apoptotic cells including spermatogonia and spermatocytes (mainly pachytene spermatocytes). Probably, apoptosis in the seminiferous epithelium is required for the normal course of spermatogenesis in adult animals $[4,5,59]$ to maintain the critical ratio of cell numbers between Sertoli and germ cells. During the first wave of spermatogenesis, a short phase (culminating in the third or fourth week of life in rat) of highly increased apoptosis takes place involving mainly spermatocytes [3]. However, the absence of apoptosis in 22 PND F1:Fin group in contrast to intensification of this process in 22 PND F1:Control could have a negative impact on the spermatogonium-to-spermatocyte ratio. The altered level of germ cell apoptosis within testis of the F1:Fin rats in comparison to the control animals observed in our study confirms previous studies on influence of anti-androgenic endocrine disruptors on male reproductive system $[39,40]$. The administration of vincozolin (an androgen receptor antagonist) to pregnant rats during the embryonic sex determination (embryonic day 8-14 it the rat) reduced the spermatogenic capacity by decreasing germ cell survival in the subsequent F1 adult male offspring [40] or even resulted in transgenerational phenotype in subsequent male offspring from F1 to F4 generation [38, 39].

Our study confirmed the results of previous studies which showed age-dependent significant alterations of androgens concentration. It is well known that the hormonal activity of testis changes during animal's life, and plasma testosterone concentration in pubertal rats is higher than in adult ones [61-63]. The age-dependent alterations of androgen levels are related to the type, number and activity of Leydig cells [64-67]. The immature and mature adult-type Leydig cells produce testosterone 4 and 30 times more testosterone, respectively, that the progenitor Leydig cells [65] which are mainly responsible for $5 \alpha$-reduced androgens release $[64,65]$. The differences in androgen levels between the F1:Fin and F1:Control groups of rats could be related to results of studies which explored the prenatal exposures to anti-androgenic endocrine disruptor like flutamide [68] or vinclozolin [40] that reduced serum testosterone concentration in adult animals. More- over, decreased T and DHT levels in F1:Fin rats as compared to F1:Control group in $22^{\text {nd }}$ postnatal day could be linked with the different apoptosis index in seminiferous epithelium of these animals. In general, gonadotropins and androgens are known as testicular cell survival factors [69]. Exposure of animals to ethane 1,2-dimetanesualfonate (EDS), a Leydig cell toxicant, results in testosterone-depended germ cell apoptosis [70-72]. It has to be noted that various mechanism of testicular cells apoptosis has been observed. For instance, the Leydig cell death does not involve Fas, in opposite to apoptosis of germ cell [72] that expressed Fas acting with its ligand (FasL) on Sertoli cells [73]. The testosterone supplementation of EDS-treated rats may play an important role in germ cell survival via suppression of Fas [72]. On opposite site, the fetal exposure of male rats to bisphenol A (BPA) that interferences with endogenous estrogens did not reduce testosterone levels but led to decrease of testis weight and presence of immature cells of spermatic lineage within the lumen of seminiferous tubules [37]. Another report showed that DHT acts as an apoptotic signaling modulator in immature rat Sertoli cells: treatment DHT resulted in down-regulation of p53, Bax, caspase 9 and 3 mRNAs [74]. The progression or regression of cell death is very important for proper tissue physiology. It was documented that apoptosis blockade could result in the atrophy of the seminiferous epithelium and finally lead to infertility [75]. Taken together, the mechanism of testicular cells apoptosis may be dependent on the type of the cell, the type of the androgen or the type of the endocrine disruptor.

The diverse changes in blood and intratesticular androgen levels (increase and decrease, respectively) during postnatal development of the F1:Fin rats in comparison to F1:Control animals could be also related to androgen-binding protein (ABP). In the conventional meaning, $A B P$ increases the concentration of androgens in the seminiferous tubule to promote spermatogenesis. The in vitro and in vivo experiments demonstrate that testosterone increased the ABP mRNA and protein in Sertoli cells and promoted the secretion of ABP; and removal of testosterone from culturing medium induced autophagy of $\mathrm{ABP}$ by Sertoli cells [76]. In the light of this report, it could be possible that the fall of intratesticular androgen levels in the F1:Fin groups, that was initiated in 3-4 week of postnatal life and it has been intensified in mature testis could have resulted in the excess of free, ABP-unbound androgens that could have been released directly into circulation. However, this hypothesis needs to be confirmed experimentally.

In summary, (i) the difficulties in obtaining male offspring from female rats fertilized by fina- 
steride-treated male rats, (ii) the changes in hormonal profiles, and (iii) the changes in TUNEL-positive testicular cell numbers allow us to conclude that finasteride treatment of male adult rats may not only cause a decrease in the fertility of parental rats, but also could lead to incorrect, androgen-sensitive course of spermatogenesis in their offspring.

\section{Acknowledgements}

This work was financed by the Pomeranian Medical University within the framework of the "Young Scientist" program (MB-167-28/11).

\section{References}

1. Clermont Y, Perey B. Quantitative study of the cell population of the seminiferous tubules in immature rats. Am J Anat. 1957;100:241-267. PMID: 13435229.

2. de Rooij DG. Proliferation and differentiation of spermatogonial stem cells. Reproduction. 2001;121:347-354. doi: 10.1530/ rep. 0.1210347 .

3. Jahnukainen K, Chrysis D, Hou M et al. Increased apoptosis occurring during the first wave of spermatogenesis is stage-specific and primarily affects midpachytene spermatocytes in the rat testis. Biol Reprod. 2004;70:290-296. doi: 10.1095/biolreprod.103.018390.

4. Phillips BT, Gassei K, Orwig KE. Spermatogonial stem cell regulation and spermatogenesis. Philos Trans $R$ Soc Lond B Biol Sci. 2010;365:1663-1678. doi: 10.1098/rstb.2010.0026.

5. Rodriguez I, Ody C, Araki K, Garcia I, Vassalli P. An early and massive wave of germinal cell apoptosis is required for the development of functional spermatogenesis. EMBO J. 1997;16:2262-2270. doi: 10.1093/emboj/16.9.2262.

6. Morales A, Mohamed F, Cavichia JC. Apoptosis and blood-testis barrier during the first spermatogenic wave in the pubertal rat. Anat Rec (Hoboken). 2007;290:206-214. doi: 10.1002/ar.20417.

7. Russell LD, Bartke A, Goh JC. Postnatal development of the Sertoli cell barrier, tubular lumen, and cytoskeleton of Sertoli and myoid cells in the rat and their relationship to tubular fluid secretion and flow. Am J Anat. 1989;84:179-189. PMID: 2750675.

8. Patrão MT, Silva EJ, Avellar MC. Androgens and the male reproductive tract: an overview of classical roles and current perspectives. Arq Bras Endocrinol Metabol. 2009;53:934-945. doi: $10.1590 /$ S0004-27302009000800006.

9. Miller WL, Auchus RJ. The molecular biology, biochemistry, and physiology of human steroidogenesis and its disorders. Endocr Rev. 2011;32:81-151. doi: 10.1210/er.2010-0013.

10. Pratis K, O’Donnell L, Ooi GT, McLachlan RI, Robertson DM. Enzyme assay for 5alpha-reductase type 2 activity in the presence of 5alpha-reductase type 1 activity in rat testis. J Steroid Biochem Mol Biol. 2000;75:75-82. doi: 10.1016/ $\underline{\text { S0960-0760(00)00139-4. }}$

11. Metcalf BW, Levy MA, Holt DA. Inhibitor of steroid 5-reductase in benign prostatic hyperplasia, male pattern baldness and acne. Trends Pharmacol Sci. 1989;10:491-495. PMID: 2482561.

12. The Finasteride Male Pattern Hair Loss Group Study. Long-term (5-year) multinational experience with finasteride $1 \mathrm{mg}$ in the treatment of men with androgenic alopecia. Eur. J Dermatol. 2002;12:38-49. PMID: 11809594.
13. Gupta AK, Charrette A. The efficacy and safety of $5 \alpha$-reductase inhibitors in androgenetic alopecia: a network meta-analysis and benefit-risk assessment of finasteride and dutasteride. J Dermatolog Treat. 2014;25:156-161. doi: $\underline{10.3109 / 09546634.2013 .813011 .}$.

14. Sato A, Takeda A. Evaluation of efficacy and safety of finasteride $1 \mathrm{mg}$ in 3177 Japanese men with androgenetic alopecia. J Dermatol. 2012;39:27-32. doi: 10.1111/j.13468138.2011.01378.x.

15. Gur S, Kadowitz PJ, Hellstrom WJG. Effects of 5-alpha reductase inhibitors on erectile function, sexual desire and ejaculation. Expert Opin Drug Saf. 2013;12:81-90. doi: 10.1517/14740338.2013.742885.

16. Ganzer CA, Jacobs AR, Iqbal F. Persistent sexual, emotional, and cognitive impairment post-finasteride: a survey of men reporting symptoms. Am J Mens Health. 2015;9:222-228. doi: $10.1177 / 1557988314538445$.

17. Amory JK, Wang C, Swerdloff RS et al. The effect of $5 \alpha$-reductase inhibition with dutasteride and finasteride on semen parameters and serum hormones in healthy men. J Clin Endocrinol Metab. 2007;92:1659-1665. doi: 10.1210/jc.20062203.

18. Chiba K, Yamaguchi K, Li F, Ando M, Fujisawa M. Finasteride-associated male infertility. Fertil Steril. 2011;95:1786. e9-11. doi: 10.1016/j.fertnstert.2010.12.001.

19. Liu KE, Binsaleh S, Lo KC, Jarvi K. Propecia-induced spermatogenic failure: a report of two cases. Fertil Steril. 2008;90:849.e17-9. doi: 10.1016/j.fertnstert.2007.08.026.

20. Irwig MS, Kolukula S. Persistent sexual side effects of finasteride for male pattern hair loss. J Sex Med. 2011;8:1747-1753. doi: 10.1111/j.1743-6109.2011.02255.x.

21. Irwig MS. Depressive symptoms and suicidal thoughts among former users of finasteride with persistent sexual side effects. J Clin Psychiatry. 2012;73:1220-1223. doi: 10.4088/ JCP.12m07887.

22. Tu HY, Zini A. Finasteride-induced secondary infertility associated with sperm DNA damage. Fertil Steril. 2011;95:2125. e13-4. doi: 10.1016/j.fertnstert.2010.12.061.

23. Şalvarci A, Istanbulluoğlu O. Secondary infertility due to use of low-dose finasteride. Int Urol Nephrol. 2013;45:83-85. doi: 10.1007/s11255-012-0315-9.

24. Collodel G, Scapigliati G, Moretti E. Spermatozoa and chronic treatment with finasteride: a TEM and FISH study. Arch Androl. 2007;53:229-233. PMID: 17852047.

25. Cukierski MA, Sina JL, Prahalada S et al. Decreased fertility in male rats administered the 5 alpha-reductase inhibitor, finasteride, is due to deficits in copulatory plug formation. Reprod Toxicol. 1991;5:353-362. doi: 10.1016/0890-6238(91)90094-V.

26. O'Donnell L, Pratis K, Stanton PG, Robertson DM, McLachlan RI. Testosterone-dependent restoration of spermatogenesis in adult rats in impaired by $5 \alpha$-reductase inhibitor. J Androl. 1999;20:109-117. doi: 10.1002/j.1939-4640.1999.tb02503.x.

27. Bradshaw WG, Baum MJ, Awh CC. Attenuation by a 5 alpha-reductase inhibitor of the activational effect of testosterone propionate on penile erections in castrated male rats. Endocrinology. 1981;109:1047-1051. doi: 10.1210/endo109-4-1047.

28. Lugg JA, Rajfer J, González-Cadavid NF. Dihydrotestosterone is the active androgen in the maintenance of nitric oxide-mediated penile erection in the rat. Endocrinology. 1995;136:1495-1501. doi: $10.1210 /$ endo.136.4.7534702.

29. Phillips KP, Foster WG. Key developments in endocrine disrupter research and human health. J Toxicol Environ Health B Crit Rev. 2008;11:322-344. doi: 10.1080/1093740070187 6194. 
30. Cowin PA, Foster PMD, Risbridger GP. Endocrine disruption in the male. In: Gore AC, ed. Endocrine Disrupting Chemicals. From Basic Research to Clinical Pratice. Humana Press: Totowa, NJ; 2007:33-52.

31. Kolasa A, Marchlewicz M, Wenda-Różewicka L, Wiszniewska B. DHT deficiency perturbs the integrity of the rat seminiferous epithelium by disrupting tight and adherens junctions. Folia Histochem Cytobiol. 2011;49:62-71. PMID: 21526491.

32. Ashby J, Tinwell H, Odum J, Lefevre P. Natural variability and the influence of concurrent control values on the detection and interpretation of low-dose or weak endocrine toxicities. Environ Health Perspect. 2004;112:847-853. PMID: 15175171.

33. Gao W, Kearbey JD, Nair VA et al. Comparison of the pharmacological effects of a novel selective androgen receptor modulator, the 5alpha-reductase inhibitor finasteride, and the anti-androgen hydroxyl flutamide in intact rats: new approach for benign prostate hyperplasia. Endocrinology. 2004;145:5420-5428. doi: 10.1210/en.2004-0627.

34. Piotrowska K, Baranowska-Bosiacka I, Marchlewicz M et al. Changes in male reproductive system and mineral metabolism induced by soy isoflavones administered to rats from prenatal life until sexual maturity. Nutrition. 2011;27:372-379. doi: 10.1016/j.nut.2010.03.010.

35. Sharpe RM, Franks S. Environment, lifestyle and infertility - an inter-generational issue. Review Nat Cell Biol. 2002;4(Suppl):33-40. doi: 10.1016/j.nut.2010.03.010.

36. Sikka SC, Wang R. Endocrine disruptors and estrogenic effects on male reproductive axis. Asian J Androl. 2008;10:134-145. doi: 10.1111/j.1745-7262.2008.00370.x.

37. Gámez JM, Penalba R, Cardoso $\mathrm{N}$ et al. Low dose of bisphenol A impairs the reproductive axis of prepuberal male rats. J Physiol Biochem. 2014;70:239-246. doi: 10.1007/ s13105-013-0298-8.

38. Skinner MK, Anway MD. Seminiferous cord formation and germ-cell programming: epigenetic transgenerational actions of endocrine disruptors. Ann NY Acad Sci. 2005;1061:18-32. doi: 10.1196/annals.1336.004.

39. Anway MD, Memon MA, Uzumcu M et al. Transgenerational effect of the endocrine disruptor vinclozolin on male spermatogenesis. J Androl. 2006;27:868-879. doi: 10.2164/ jandrol.106.000349.

40. Uzumcu MI, Suzuki H, Skinner MK. Effect of the anti-androgenic endocrine disruptor vinclozolin on embryonic testis cord formation and postnatal testis development and function. Reprod Toxicol. 2004;18:765-774. doi: 10.1016/j. reprotox.2004.05.008.

41. Prahalada S, Tarantal AF, Harris GS et al. Effects of finasteride, a type 25 -alpha reductase inhibitor, on fetal development in the rhesus monkey (Macaca mulatta). Teratology. 1997;55:119-131. doi: 10.1002/(SICI)10969926(199702)55:2<119::AID-TERA1>3.0.CO;2-Z.

42. Bowman CJ, Barlow NJ, Turner KJ, Wallace DG, Foster PM. Effects of in utero exposure to finasteride on androgen-dependent reproductive development in the male rat. Toxicol Sci. 2003;74:393-406. doi: $10.1093 /$ toxsci/kfg128.

43. Laborde E, Brannigan RE. Effect of 1-mg dose of finasteride on spermatogenesis and pregnancy.J Androl. 2010;31:e1-e2. doi: 10.2164 /jandrol.109.009381.

44. Ricci G, Martinelli M, Luppi S et al. Finasteride and fertility: case report and review of the literature. J Drugs Dermatol. 2012;11:1511-1513. PMID: 23377525.

45. Gude D. Finasteride and male fertility. J Hum Reprod Sci. 2011;4:101-102. doi: 10.4103/0974-1208.86093.

46. Bloomer LD, Nelson CP, Eales J et al. Male-specific region of the Y chromosome and cardiovascular risk: phylogenetic analysis and gene expression studies. Arterioscler Thromb Vasc Biol. 2013;33:1722-1727. doi: 10.1161/ATVBAHA.113.301608.

47. Krausz C. Polymorphism and male infertility. In: Carrell DT, ed. The genetics of male infertility. Part IV. Clinical applications of the study of the genetics of male infertility. Human Press Inc.: New Jersey; 2007:275-291.

48. Wilson MA, Makova KD. Genomic analyses of sex chromosome evolution. Annu Rev Genomics Hum Genet. 2009;10:333354. doi: 10.1146/annurev-genom-082908-150105.

49. Touré A, Clemente EJ, Ellis P et al. Identification of novel Y chromosome encoded transcripts by testis transcriptome analysis of mice with deletions of the $\mathrm{Y}$ chromosome long arm. Genome Biol. 2005;612:R102. doi: 10.1016/j.cell.2014.09.052.

50. Mazeyrat S, Mitchell MJ. Rodent Y chromosome TSPY gene is functional in rat and non-functional in mouse. Hum $\mathrm{Mol}$ Genet. 1998;7:557-562. doi: 10.1093/hmg/7.3.557.

51. Yue XP, Dechow C, Chang TC et al. Copy number variations of the extensively amplified Y-linked genes, HSFY and ZNF$280 \mathrm{BY}$, in cattle and their association with male reproductive traits in Holstein bulls. BMC Genomics. 2014;15:113. doi: 10.1186/1471-2164-15-113.

52. Bhowmick BK, Satta Y, Takahata N. The origin and evolution of human ampliconic gene families and ampliconic structure. Genome Res. 2007;17:441-450. doi: 10.1101/gr.5734907.

53. Ebensperger LA. Strategies and counterstrategies to infanticide in mammals. Biol Rev. 1998;73:321-346. doi: 10.1111/j.1469-185X.1998.tb00034.x.

54. Ishihara K, Warita K, Tanida T, Sugawara T, Kitagawa H, Hoshi N. Does paternal exposure to 2,3,7,8-Tetrachlorodibenzo-p-Dioxin (TCDD) affect the sex ratio of offspring? $J$ Vet Med Sci. 2007;69:347-352. doi: 10.1292/jvms.69.347.

55. Mocarelli P, Gerthoux PM, Ferrari E et al. Paternal concentrations of dioxin and sex ratio of offspring. Lancet. 2000;355:1858-1863. doi: 10.1016/S0140-6736(00)02290-X.

56. Ryan JJ, Amirova Z, Carrier G. Sex ratios of children of Russian pesticide producers exposed to dioxin. Environ Health Perspect. 2002;110:A699-A701. PMID: 12417498.

57. Trasler JM, Doerksen T. Teratogen update: paternal exposures-reproductive risks. Teratology. 1999;60:161-172. doi: 10.1002/(SICI)1096-9926(199909)60:3<161::AID-TERA12>3.0.CO;2-A.

58. Zhang Y, Calvo E, Martel C, Luu-The V, Labrie F, Tchernof A. Response of the adipose tissue transcriptome to dihydrotestosterone in mice. Physiol Genomics. 2008;35:254-261. doi: 10.1152/physiolgenomics.00257.2007.

59. Jeyaraj DA, Grossman G, Petrusz P. Dynamics of testicular germ cell apoptosis in normal mice and transgenic mice overexpressing rat androgen-binding protein. Reprod Biol Endocrinol. 2003;1:48. doi: 10.1186/1477-7827-1-48.

60. Miething A. Germ-cell death during prespermatogenesis in the testis of golden hamster. Cell Tissue Res. 1992;267:583-590. PMID: 1571969.

61. Resko JA, Feder HH, Goy RW. Androgen concentrations in plasma and testis of developing rats. $J$ Endocrinol. 1968;40:485-491. PMID: 5643421.

62. Knorr DW, Vanha-Perittula T, Lipsett MB. Structure and function of rat testis through pubescence. Endocrinology. 1970;86:1298-1304. doi: 10.1210/endo-86-6-1298.

63. Grota LJ. Effect of age and experience on plasma testosterone. Neuroendocrinology. 1971;8:136-143. PMID: 5555965.

64. Tapanainen JS, Tilly JL, Vihko KK, Hsueh AJ. Hormonal control of apoptotic cell death in the testis: gonadotropins and androgens as testicular cell survival factors. Mol Endocrinol. 1993;7:643-650. doi: 10.1210/mend.7.5.8316250. 
65. Ge RS, Hardy MP. Variation in the end products of androgen biosynthesis and metabolism during postnatal differentiation of rat Leydig cells. Endocrinology. 1998;139:3787-3795. doi: 10.1210/endo.139.9.6183.

66. Ge RS, Dong Q, Sottas CM, Papadopoulos V, Zirkin BR, Hardy MP. In search of rat stem Leydig cells: identification, isolation, and lineage-specific development. Proc Natl Acad Sci USA. 2006;103:2719-2724. doi: 10.1073/pnas.0507692103.

67. Hardy MP, Zirkin BR, Ewing LL. Kinetic studies on the development of the adult population of Leydig cells in testes of the pubertal rat. Endocrinology. 1989;124:762-770. doi: 10.1210/endo-124-2-762.

68. Kotula-Balak M, Hejmej A, Kopera I, Lydka M, Bilinska B. Prenatal and neonatal exposure to flutamide affects function of Leydig cells in adult boar. Domest Anim Endocrinol. 2012;42:142-154. doi: 10.1016/j.domaniend.2011.11.002.

69. Tapanainen J, Kuopio T, Pelliniemi LJ, Huhtaniemi I. Rat testicular endogenous steroids and number of Leydig cells between the fetal period and sexual maturity. Biol Reprod. 1984;31:1027-1035. doi: 10.1095/biolreprod31.5.1027.

70. Henriksén K, Hakovirta H, Parvinen M. Testosterone inhibits and induces apoptosis in rat seminiferous tubules in a stage -specific manner: in situ quantification in squash preparations after administration of ethane dimethane sulfonate. Endocrinology. 1995;136:3285-3291. doi: 10.1210/endo.136.8.7628362.
71. Bakalska M, Atanassova N, Koeva Y, Nikolov B, Davidoff M. Induction of male germ cell apoptosis by testosterone withdrawal after ethane dimethanesulfonate treatment in adult rats. Endocr Regul. 2004;38:103-110. PMID: 15693288.

72. Nandi S, Banerjee PP, Zirkin BR. Germ cell apoptosis in the testes of Sprague Dawley rats following testosterone withdrawal by ethane 1,2-dimethanesulfonate administration: relationship to Fas? Biol Reprod. 1999;61:70-75. doi: 10.1095/ biolreprod61.1.70.

73. Lee J, Richburg JH, Younkin SC, Boekelheide K. The Fas system is a key regulator of germ cell apoptosis in the testis. Endocrinology. 1997;138:2081-2088. doi: 10.1210/ endo.138.5.5110.

74. Simöes VL, Alves MG, Martins AD et al. Regulation of apoptotic signaling pathways by $5 \alpha$-dihydrotestosterone and $17 \beta$-estradiol in immature rat Sertoli cells. J Steroid Biochem Mol Biol. 2013;135:15-23. doi: 10.1016/j.jsbmb.2012.11.019.

75. Knudson CM, Tung KS, Tourtellotte WG, Brown GA, Korsmeyer SJ. Bax-deficient mice with lymphoid hyperplasia and male germ cell death. Science. 1995;270:96-99. doi: $\underline{10.1126 /}$ science.270.5233.96.

76. Ma Y, Yang HZ, Xu LM, Huang YR, Dai HL, Kang XN. Testosterone regulates the autophagic clearance of androgen binding protein in rat Sertoli cells. Sci Rep. 2015;5:8894. doi: $\underline{10.1038 / \text { srep08894. }}$.

Submitted: 5 May, 2015

Accepted after reviews: 10 September, 2015 Available as AoP: 15 September, 2015 